\title{
A New Voltage-Mode Universal Biquadratic Filter Using Single UVC
}

\author{
Kanhaiya Lal Pushkar¹, Kavya Gupta ${ }^{2}$, Pinky Vivek ${ }^{3}$ \\ ${ }^{1}$ Department of Electronics and Communication Engineering, Maharaja Agrasen Institute of Technology, Rohini, New Delhi, India \\ ${ }^{2}$ Electronics and Communication Engineering Cell, Radiance Edutech ${ }^{\mathrm{TM}}$, DDA Market, Paschim Vihar, Delhi, India \\ ${ }^{3}$ Department of Electronics and Communication Engineering, Al-Falah University, Faridabad, India \\ Email: klpushkar17@gmail.com, kavyagpt17@gmail.com, pinky.vivek18@gmail.com
}

How to cite this paper: Pushkar, K.L., Gupta, K. and Vivek, P. (2017) A New Voltage-Mode Universal Biquadratic Filter Using Single UVC. Circuits and Systems, 8, 275-284.

https://doi.org/10.4236/cs.2017.812020

Received: November 8, 2017

Accepted: December 24, 2017

Published: December 27, 2017

Copyright (c) 2017 by authors and Scientific Research Publishing Inc. This work is licensed under the Creative Commons Attribution International License (CC BY 4.0).

http://creativecommons.org/licenses/by/4.0/

(c) (i) Open Access

\begin{abstract}
The paper presents a new universal biquadratic filter using single universal voltage conveyor (UVC), two resistors and two capacitors. The offered structure has three inputs and one output and can realise all the five basic biquadratic filters: high-pass (HP), low-pass (LP), band-reject (BR), band-pass (BP) and all-pass (AP) from the same circuit topology. The proposed universal filter also provides following advantageous features, not available simultaneously in any UVC based universal biquadratic filter so far: (i) low active and passive sensitivities, (ii) independent control of natural frequency $\left(\omega_{0}\right)$ and bandwidth (BW) and (iii) no requirement of any component matching condition and inversion of input signal(s) (as needed in most of the earlier reported structures). The workability of proposed structure has been presented by SPICE (Version 16.5) simulation using $0.18 \mu \mathrm{m}$ TSMC technology.
\end{abstract}

\section{Keywords}

Analog Circuit, Universal Voltage Conveyor, Voltage-Mode, Filters

\section{Introduction}

Interest in the design of multi-input single-output (MISO) or single-input multioutput (SIMO), current-mode (CM) or voltage-mode (VM) universal filter configurations have been emerging, due to their flexibility and versatility for practical applications [1]. In literature [2]-[7], filter structures using different active building blocks/devices (such as current differencing transconductance amplifier, current differencing buffered amplifier, modified current feedback operational amplifier and current feedback operational amplifier) have been presented over the past few years. In ref [8], Herenscar, Koton and Vrba have presented multi- 
function filter structures, employing three UVCs could realize only three basic filters (i.e. LP, HP, and BP). In ref [9], Minarcik and Vrba have proposed three multi-function filter structures: i) realize three basic filters i.e. LP, HP, and BP using three UVCs ii) realize four basic filters i.e. LP, HP, BP and, AP using two UVCs which can iii) four basic filters i.e. LP, HP, BP and, AP, employing single UVC. Filter structures presented in references [8] [9] are unable to realize all the basic biquadratic filter functions from single topology (i.e. LP, HP, BP, BR and AP).

In ref. [10], Pushkar and Gupta presented another universal filter in which all basic filter functions (LP, HP, BP, BR and AP) are realised however, the normalized gain of bandpass filter is approximately half which limits it's applications, component matching and scaling of input signal is also required. Therefore, the purpose of this paper is to propose a new universal MISO-type VM biquad with three inputs and one output, which can realize all basic filter functions, namely: LP, HP, BP, BR and AP with no component matching and scaling of input signal is required. Comparison with other previously known MISO-type biquads using different active building blocks is shown in Table 2. The proposed filter is verified by SPICE (Version 16.5) simulations using 0.18 $\mu \mathrm{m}$ TSMC technology.

\section{Proposed Filter Configuration}

The Universal Voltage Conveyor is a 6-port active element with one voltage input $x$, two difference current inputs $\left(y^{+}, y^{-}\right)$, two mutually inverse voltage outputs $\left(z^{+}, z^{-}\right)$, and one auxiliary port $w$. Figure $1(\mathrm{a})$ and Figure $1(\mathrm{~b})$ show the

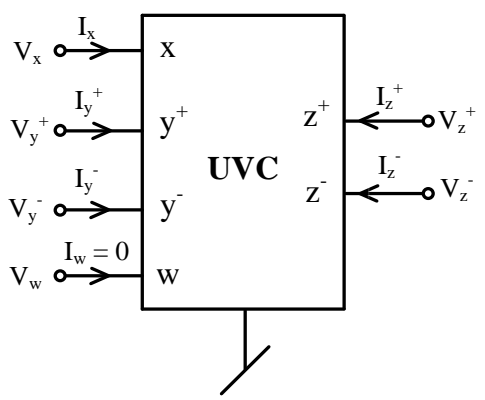

(a)

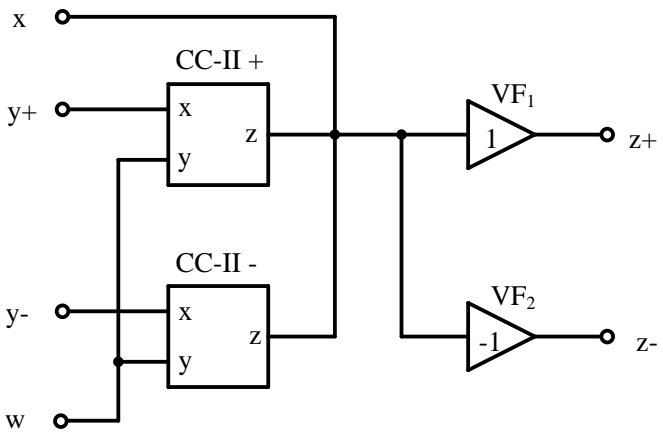

(b)

Figure 1. (a) Schematic symbol of UVC. (b) Ideal circuit model of UVC [11]. 
schematic symbol and ideal circuit model of UVC respectively. The relationship between port currents and voltages of a six port UVC is given in the following matrix.

$$
\left(\begin{array}{c}
I_{x} \\
I_{w} \\
V_{y^{+}} \\
V_{y^{-}} \\
V_{z^{+}} \\
V_{z^{-}}
\end{array}\right)=\left(\begin{array}{cccccc}
0 & 0 & 1 & -1 & 0 & 0 \\
0 & 0 & 0 & 0 & 0 & 0 \\
0 & 1 & 0 & 0 & 0 & 0 \\
0 & 1 & 0 & 0 & 0 & 0 \\
1 & 0 & 0 & 0 & 0 & 0 \\
-1 & 0 & 0 & 0 & 0 & 0
\end{array}\right)\left(\begin{array}{c}
V_{x} \\
V_{w} \\
I_{y^{+}} \\
I_{y^{-}} \\
I_{z^{+}} \\
I_{z^{-}}
\end{array}\right)
$$

A routine circuit analysis (assuming ideal UVC) of Figure 2 yields the following expression for the voltage transfer function of the biquad:

$$
V_{o}=\frac{V_{2}\left(s^{2}\right)-V_{1}\left(\frac{s}{C_{2} R_{2}}\right)+V_{3}\left(\frac{1}{C_{1} C_{2} R_{1} R_{2}}\right)}{s^{2}+\frac{s}{C_{2} R_{2}}+\frac{1}{R_{1} R_{2} C_{1} C_{2}}}
$$

From Equation (2), second order filter functions (LP, HP, BP, BR and AP) can be realized.

1) If $V_{3}=V_{\text {in }}, V_{2}=V_{1}=0$ (grounded), a low pass filter can be realized.

$$
\left.T(s)\right|_{L P}=\frac{\frac{1}{C_{1} C_{2} R_{1} R_{2}}}{D(s)}
$$

2) If $V_{2}=V_{\text {in }}$ and $V_{3}=V_{1}=0$ (grounded), a high pass filter can be realized.

$$
\left.T(s)\right|_{H P}=\frac{s^{2}}{D(s)}
$$

3) If $V_{1}=V_{\text {in }}$ and $V_{2}=V_{3}=0$ (grounded), a band pass filter can be realized.

$$
\left.T(s)\right|_{B P}=\frac{-\frac{s}{C_{2} R_{2}}}{D(s)}
$$

4) If $V_{3}=V_{2}=V_{\text {in }}$ and $V_{1}=0$, a band reject filter can be realized.

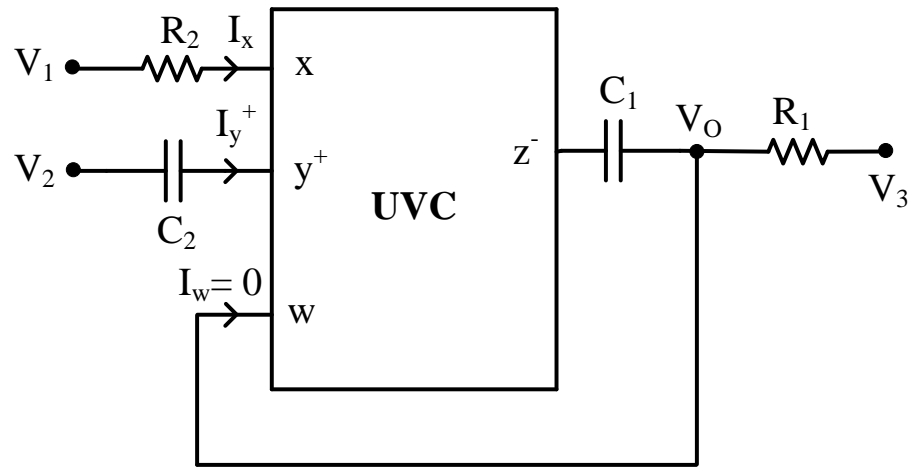

Figure 2. The proposed MISO-type voltage-mode universal biquad. 


$$
\left.T(s)\right|_{B R}=\frac{s^{2}+\frac{1}{R_{1} R_{2} C_{1} C_{2}}}{D(s)}
$$

5) If $V_{1}=V_{2}=V_{3}=V_{\text {in }}$, a all pass filter can be realized.

$$
\left.T(s)\right|_{A P}=\frac{s^{2}-\frac{s}{C_{2} R_{2}}+\frac{1}{R_{1} R_{2} C_{1} C_{2}}}{D(s)}
$$

where: $D(s)=s^{2}+\frac{s}{C_{2} R_{2}}+\frac{1}{R_{1} R_{2} C_{1} C_{2}}$

The expressions for quality factor $\left(Q_{0}\right)$, bandwidth $(B W)$ and natural frequency $\left(\omega_{0}\right)$, respectively are given by:

$$
Q_{0}=\sqrt{\frac{R_{2} C_{2}}{R_{1} C_{1}}}, B W=\frac{1}{C_{2} R_{2}}, \omega_{0}=\sqrt{\frac{1}{R_{1} R_{2} C_{1} C_{2}}}
$$

From (3), it can be observed that after adjusting $B W$ by $R_{2}, \omega_{0}$ can independently be controlled through $R_{1}$. Furthermore, it is seen that no inversion of input signal(s) and no component matching condition is required while realizing any of the five filter functions.

In the ideal case, the various sensitivities of $\omega_{0}$ and $B W$ with respect to $R_{1}, R_{2}$, $C_{1}$, and $C_{2}$ are found to be:

$$
\begin{gathered}
S_{C_{1}}^{\omega_{0}}=S_{C_{2}}^{\omega_{0}}=S_{R_{1}}^{\omega_{0}}=S_{R_{2}}^{\omega_{0}}=-\frac{1}{2} \\
S_{C_{1}}^{B W}=0, S_{C_{2}}^{B W}=-1, S_{R_{1}}^{B W}=0, S_{R_{2}}^{B W}=-1
\end{gathered}
$$

\section{Non-Ideal Analysis and Sensitivity Performance}

Taking into account the non-idealities of UVC, the relationship between the port voltages and currents is shown by the hybrid matrix:

$$
\left(\begin{array}{c}
I_{x} \\
I_{w} \\
V_{y^{+}} \\
V_{y^{-}} \\
V_{z^{+}} \\
V_{z^{-}}
\end{array}\right)=\left(\begin{array}{cccccc}
0 & 0 & \alpha_{1} & -\alpha_{2} & 0 & 0 \\
0 & 0 & 0 & 0 & 0 & 0 \\
0 & \delta_{1} & 0 & 0 & 0 & 0 \\
0 & \delta_{2} & 0 & 0 & 0 & 0 \\
\gamma_{1} & 0 & 0 & 0 & 0 & 0 \\
-\gamma_{2} & 0 & 0 & 0 & 0 & 0
\end{array}\right)\left(\begin{array}{c}
V_{x} \\
V_{w} \\
I_{y^{+}} \\
I_{y^{-}} \\
I_{z^{+}} \\
I_{z^{-}}
\end{array}\right)
$$

where $\alpha_{j}=1-\varepsilon_{i j}$ and $\delta_{j}=1-\varepsilon_{v 1 j}, \gamma_{j}=1-\varepsilon_{v 2 j}$ for $j=1,2$. Here $\varepsilon_{i j}\left(\left|\varepsilon_{i j}\right| \ll 1\right)$ and $\varepsilon_{v 1 j}, \quad \varepsilon_{v 2 j} \quad \varepsilon_{i j}\left(\left|\varepsilon_{v 1 j}\right|,\left|\varepsilon_{v 2 j}\right| \ll 1\right)$ represent the current and voltage tracking errors of the UVC respectively. The parasitic present on the low impedance ports $\left(y^{+}, y^{-}, z^{+}, z^{-}\right)$are quite low as compared to the resistances on the other ports ( $w$ and $x$ ) [12]. After considering the non-idealities of the UVC, given by the hybrid matrix of Equation (6), transfer function presented in Equation (2) can be modified as follows: 


$$
\begin{gathered}
V_{0}=\frac{\alpha_{1} \gamma_{2} V_{2}\left(s^{2} C_{1} C_{2}\right)-\gamma_{2} V_{1}\left(s \frac{C_{1}}{R_{2}}\right)+\frac{V_{3}}{R_{1}}\left(s C_{x}+\frac{1}{R_{2}}+\frac{1}{R_{x}}\right)}{s^{2}\left(\alpha_{1} \delta_{1} \gamma_{2} C_{1} C_{2}+C_{1} C_{x}+C_{w} C_{x}\right)+s\left(\left(C_{1}+C_{w}\right)\left(\frac{1}{R_{2}}+\frac{1}{R_{x}}\right)+C_{x}\left(\frac{1}{R_{1}}+\frac{1}{R_{w}}\right)\right)+\left(\frac{1}{R_{2}}+\frac{1}{R_{x}}\right)\left(\frac{1}{R_{1}}+\frac{1}{R_{w}}\right)} \\
\omega_{0}=\sqrt{\frac{\left(\frac{1}{R_{2}}+\frac{1}{R_{x}}\right)\left(\frac{1}{C_{1} C_{x}+C_{w} C_{x}+\alpha_{1} \delta_{1} \gamma_{2} C_{1} C_{2}}\right)}{R_{w}}} \\
B W=\frac{\left(C_{1}+C_{w}\right)\left(\frac{1}{R_{2}}+\frac{1}{R_{x}}\right)+C_{x}\left(\frac{1}{R_{1}}+\frac{1}{R_{w}}\right)}{C_{1} C_{x}+C_{w} C_{x}+\alpha_{1} \delta_{1} \gamma_{2} C_{1} C_{2}}
\end{gathered}
$$

The sensitivity is an important performance criterion of any circuit structure. The sensitivity of Natural Frequency $\left(\omega_{0}\right)$ with respect to circuit parameters, say A is given as:

$$
S_{A}^{\omega_{0}}=\frac{A}{\omega_{0}} \frac{\partial \omega_{0}}{\partial A}
$$

Using above definition, the various active and passive sensitivities of Natural Frequency $\left(\omega_{0}\right)$ and Bandwidth $(B W)$, for the biquadratic filter, with respect to $C_{1}, C_{2}, C_{x}, C_{w}, R_{1}, R_{2}, R_{x}, R_{w}, \alpha_{1}, \delta_{1}$ and $\gamma_{2}$ are found to be:

$$
\begin{aligned}
& S_{C_{1}}^{\omega_{0}}=-\frac{1}{2}\left(\frac{C_{1} C_{x}+\alpha_{1} \delta_{1} \gamma_{2} C_{1} C_{2}}{C_{1} C_{x}+C_{w} C_{x}+\alpha_{1} \delta_{1} \gamma_{2} C_{1} C_{2}}\right), S_{C_{x}}^{\omega_{0}}=-\frac{1}{2}\left(\frac{C_{1} C_{x}+C_{w} C_{x}}{C_{1} C_{x}+C_{w} C_{x}+\alpha_{1} \delta_{1} \gamma_{2} C_{1} C_{2}}\right) \\
& S_{C_{2}}^{\omega_{0}}=-\frac{1}{2}\left(\frac{\alpha_{1} \delta_{1} \gamma_{2} C_{1} C_{2}}{C_{1} C_{x}+C_{w} C_{x}+\alpha_{1} \delta_{1} \gamma_{2} C_{1} C_{2}}\right)=S_{\alpha_{1}}^{\omega_{0}}=S_{\delta_{1}}^{\omega_{0}}=S_{\gamma_{2}}^{\omega_{0}} \\
& S_{C_{w}}^{\omega_{0}}=-\frac{1}{2}\left(\frac{C_{w} C_{x}}{C_{1} C_{x}+C_{w} C_{x}+\alpha_{1} \delta_{1} \gamma_{2} C_{1} C_{2}}\right), S_{R_{2}}^{\omega_{0}}=-\frac{1}{2}\left(\frac{1}{1+\frac{R_{2}}{R_{x}}}\right), S_{R_{x}}^{\omega_{0}}=-\frac{1}{2}\left(\frac{1}{1+\frac{R_{x}}{R_{2}}}\right) \\
& S_{R_{w}}^{\omega_{0}}=-\frac{1}{2}\left(\frac{1}{1+\frac{R_{w}}{R_{1}}}\right), S_{R_{1}}^{\omega_{0}}=-\frac{1}{2}\left(\frac{1}{1+\frac{R_{1}}{R_{w}}}\right) \\
& S_{C_{1}}^{B W}=-\frac{C_{1}\left(C_{x}^{2}\left(\frac{1}{R_{1}}+\frac{1}{R_{w}}\right)+\alpha_{1} \delta_{1} \gamma_{2} C_{2}\left(C_{1}\left(\frac{1}{R_{2}}+\frac{1}{R_{x}}\right)+C_{x}\left(\frac{1}{R_{1}}+\frac{1}{R_{w}}\right)\right)\right)}{\left(\left(C_{1}+C_{w}\right)\left(\frac{1}{R_{2}}+\frac{1}{R_{x}}\right)+C_{x}\left(\frac{1}{R_{1}}+\frac{1}{R_{w}}\right)\right)\left(C_{1} C_{x}+C_{w} C_{x}+\alpha_{1} \delta_{1} \gamma_{2} C_{1} C_{2}\right)} \\
& S_{C_{w}}^{B W}=-\frac{C_{w}\left(C_{x}^{2}\left(\frac{1}{R_{1}}+\frac{1}{R_{w}}\right)+\alpha_{1} \delta_{1} \gamma_{2} C_{2} C_{1}\left(\frac{1}{R_{2}}+\frac{1}{R_{x}}\right)\right)}{\left(\left(C_{1}+C_{w}\right)\left(\frac{1}{R_{2}}+\frac{1}{R_{x}}\right)+C_{x}\left(\frac{1}{R_{1}}+\frac{1}{R_{w}}\right)\right)\left(C_{1} C_{x}+C_{w} C_{x}+\alpha_{1} \delta_{1} \gamma_{2} C_{1} C_{2}\right)}
\end{aligned}
$$




$$
\begin{gathered}
S_{C_{x}}^{B W}=-\frac{C_{x}\left(\left(C_{1}+C_{w}\right)^{2}\left(\frac{1}{R_{2}}+\frac{1}{R_{x}}\right)+\alpha_{1} \delta_{1} \gamma_{2} C_{2} C_{1}\left(\frac{1}{R_{1}}+\frac{1}{R_{w}}\right)\right)}{\left(\left(C_{1}+C_{w}\right)\left(\frac{1}{R_{2}}+\frac{1}{R_{x}}\right)+C_{x}\left(\frac{1}{R_{1}}+\frac{1}{R_{w}}\right)\right)\left(C_{1} C_{x}+C_{w} C_{x}+\alpha_{1} \delta_{1} \gamma_{2} C_{1} C_{2}\right)} \\
S_{C_{2}}^{B W}=-\frac{\alpha_{1} \delta_{1} \gamma_{2} C_{1} C_{2}}{C_{1} C_{x}+C_{w} C_{x}+\alpha_{1} \delta_{1} \gamma_{2} C_{1} C_{2}}=S_{\alpha_{1}}^{B W}=S_{\delta_{1}}^{B W}=S_{\gamma_{2}}^{B W} \\
S_{R_{1}}^{B W}=\frac{-\frac{C_{x}}{R_{1}}}{\left(C_{1}+C_{w}\right)\left(\frac{1}{R_{2}}+\frac{1}{R_{x}}\right)+C_{x}\left(\frac{1}{R_{1}}+\frac{1}{R_{w}}\right)}, \\
S_{R_{w}}^{B W W}=\frac{-\frac{C_{x}}{R_{w}}}{\left(C_{1}+\frac{\left(C_{1}+C_{w}\right)}{R_{x}}\right.} \\
S_{R_{2}}^{B W}=\frac{\left(\frac{1}{C_{1}}+\frac{1}{R_{x}}\right)+C_{x}\left(\frac{1}{R_{1}}+\frac{1}{R_{w}}\right)}{\left(C_{1}+C_{w}\right)\left(\frac{1}{R_{2}}+\frac{1}{R_{x}}\right)+C_{x}\left(\frac{1}{R_{1}}+\frac{1}{R_{w}}\right)}
\end{gathered}
$$

Considering the typical values of various parasitic [13] e.g. $C_{x}=17.41 \mathrm{pF}$, $R_{x}=378.73 \mathrm{k} \Omega, C_{w}=4.19 \mathrm{pF}, R_{w}=88.19 \mathrm{M} \Omega, \alpha_{1}=\delta_{1}=\gamma_{2}=1$ along with $C_{1}=C_{2}=10 \mathrm{pF}, R_{1}=R_{1}=100 \mathrm{k} \Omega$, the various sensitivities are found to be $S_{C_{1}}^{\omega_{0}}=-0.253, \quad S_{C_{2}}^{\omega_{0}}=S_{\alpha_{1}}^{\omega_{0}}=S_{\delta_{1}}^{\omega_{0}}=S_{\gamma_{2}}^{\omega_{0}}=-0.143, \quad S_{C_{x}}^{\omega_{0}}=-0.355, \quad S_{C_{w}}^{\omega_{0}}=-0.104$, $S_{R_{w}}^{\omega_{0}}=-0.0056, \quad S_{R_{1}}^{\omega_{0}}=-0.495, \quad S_{R_{2}}^{\omega_{0}}=-0.395, \quad S_{R_{X}}^{\omega_{0}}=-0.104$ and $S_{C_{1}}^{B W}=$ $-0.5001, \quad S_{C_{2}}^{B W}=S_{\alpha_{1}}^{B W}=S_{\delta_{1}}^{B W}=S_{\gamma_{2}}^{B W}=-0.2861, \quad S_{C_{x}}^{B W}=-0.4981, \quad S_{C_{w}}^{B W}=-0.1484$, $S_{R_{w}}^{B W}=-0.0053, S_{R_{1}}^{B W}=-0.5006, S_{R_{2}}^{B W}=-0.4125, S_{R_{X}}^{B W}=-0.1089$. It is clearly observed that none of the active and passive sensitivities are more than one half in magnitudes for the proposed VM biquad filter.

\section{Simulation Results}

To confirm the feasibility of the presented biquadratic filter, the circuit was simulated using SPICE. The voltage and current values selected for CMOS implementation of UVC are $\pm 1.9 \mathrm{~V}$ and $100 \mu \mathrm{A}$, respectively. The passive elements were chosen as $C_{1}=C_{2}=10 \mathrm{pF}, R_{1}=R_{2}=100 \mathrm{k} \Omega$. The natural frequency $\left(\omega_{0}\right)$ and $B W$ of the proposed filter for the selected passive elements are 87.498 $\mathrm{kHz}$ and $151.266 \mathrm{kHz}$ respectively. CMOS implementation of universal voltage conveyor is shown in Figure 3 and the aspect ratios of MOSFETs used in Figure 3 are given in Table 1 [14]. CMOS UVC was implemented $0.18 \mu \mathrm{m}$ TSMC CMOS model parameters [15]. 


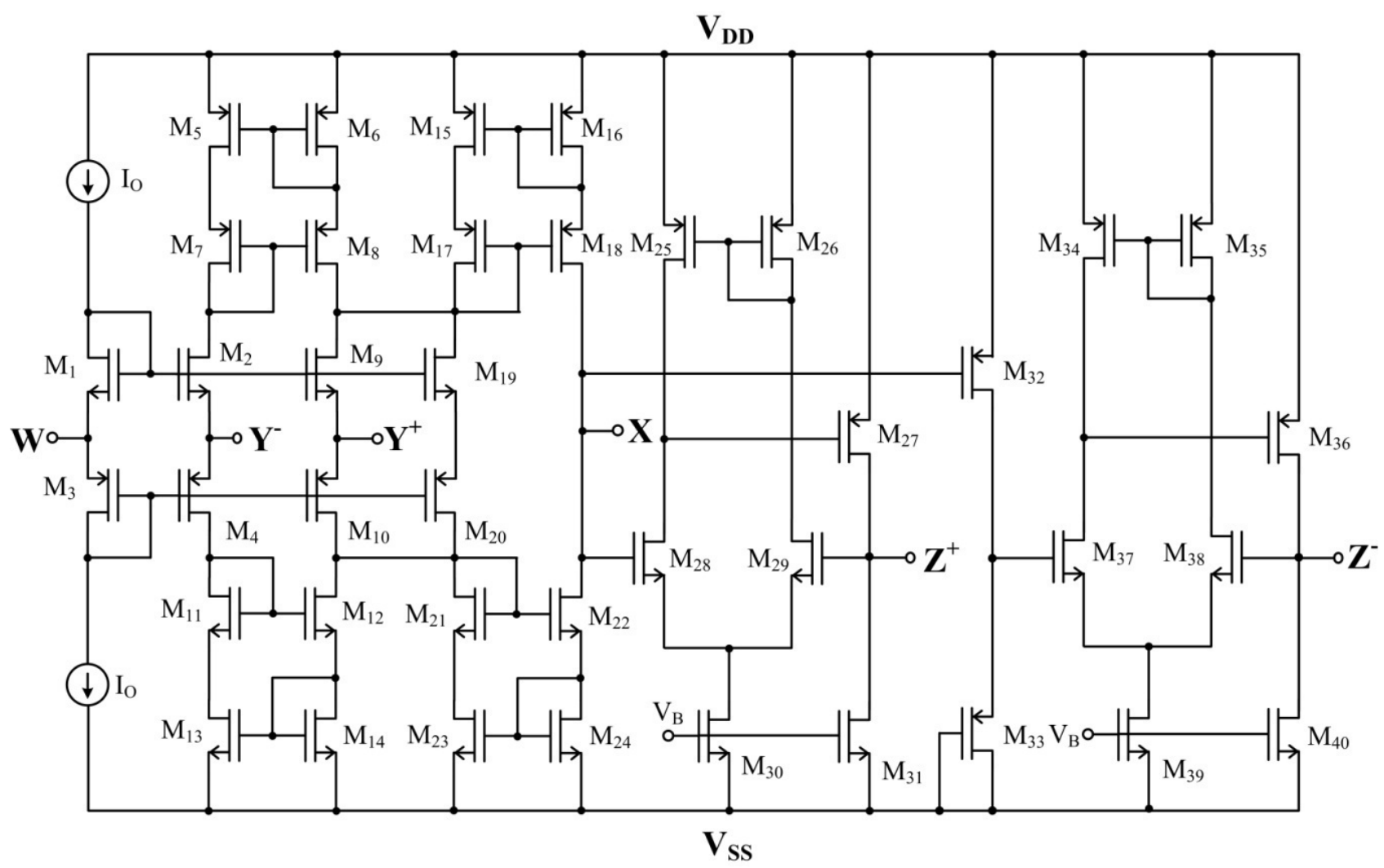

Figure 3. Implementation of CMOS structure of UVC, $\mathrm{V}_{\mathrm{DD}}=-\mathrm{V}_{\mathrm{SS}}=1.9 \mathrm{~V}, \mathrm{I}_{\mathrm{o}}=100 \mu \mathrm{A}$.

Table 1. The aspect ratios (W/L) of transistors used in Figure 3.

\begin{tabular}{cc}
\hline PMOS transistors & $\mathrm{W}(\mu \mathrm{m}) / \mathrm{L}(\mu \mathrm{m})$ \\
\hline M5-M8, M10, M15-M18, M20 & $14.0 / 0.7$ \\
M3, M4 & $28 / 0.7$ \\
M25, M26, M34, M35 & $4.0 / 0.5$ \\
M27, M36 & $10.0 / 0.5$ \\
M32, M33 & $2.1 / 1.0$ \\
\hline NMOS transistors MI, M2 & W $(\mu \mathrm{m}) / \mathrm{L}(\mu \mathrm{m})$ \\
\hline M1, M2 & $14.0 / 0.7$ \\
M9, M11-M14, M19, M21-M24 & $28 / 0.7$ \\
M28, M29, M37, M38 & $0.8 / 05$ \\
M30, M31, M39, M40 & $10 / 0.5$ \\
\hline
\end{tabular}

A comparison with other previously known MISO-type biquads using different active building blocks has been shown in Table 2, the proposed structure gives all basic filter functions and free from any matching conditions. The SPICE simulated frequency response of the biquad is shown in Figures 4-6 represent the magnitude and phase plot of APF, respectively. These plots are nearly similar to the standard second order filters: LPF, HPF, BPF, APF and BRF. Therefore, these responses confirm the validity of the proposed biquadratic filter. 
Table 2. A comparison with other previously known MISO-type biquads using different active building blocks.

\begin{tabular}{ccccc}
\hline Reference & $\begin{array}{c}\text { No. of active } \\
\text { building blocks }\end{array}$ & $\begin{array}{c}\text { External } \\
\text { resistors used }\end{array}$ & $\begin{array}{c}\text { Is realization free from } \\
\text { matching condition(s)? }\end{array}$ & $\begin{array}{c}\text { Number of standard } \\
\text { filter realized }\end{array}$ \\
\hline$[2]$ & 1 & 3 & NO & 5 \\
{$[4]$} & 1 & 4 & NO & 5 \\
{$[5]$} & 1 & 3 & NO & 5 \\
{$[6]$} & 1 & 2 & NO & 5 \\
{$[7]$} & 1 & 3 & NO & 5 \\
{$[8]$} & 3 & 5 & YES & 3 \\
& 3 & 5 & YES & (LP, HP, BP) \\
& & & & (LP, HP, BP) \\
{$[9]$} & 2 & 3 & YES & 4 \\
& 1 & 2 & YES & (LP, HP, BP, AP) \\
& 1 & 2 & NO & 4 \\
Proposed & 1 & 2 & YES & 5 \\
\hline
\end{tabular}

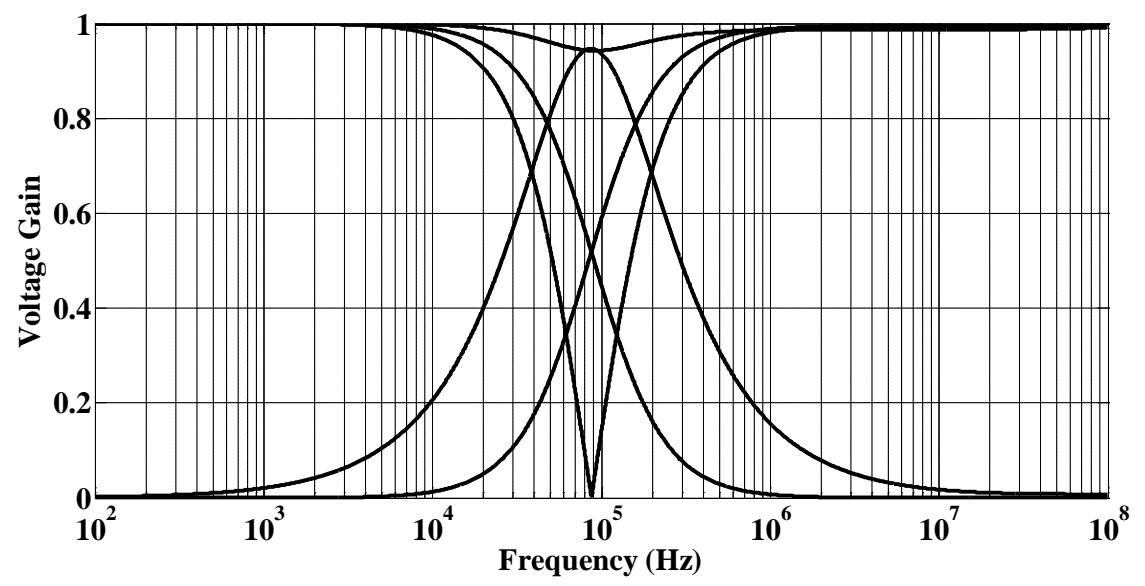

Figure 4. Frequency response of the proposed biquad filter.



Figure 5. Frequency response of all-pass filter. 


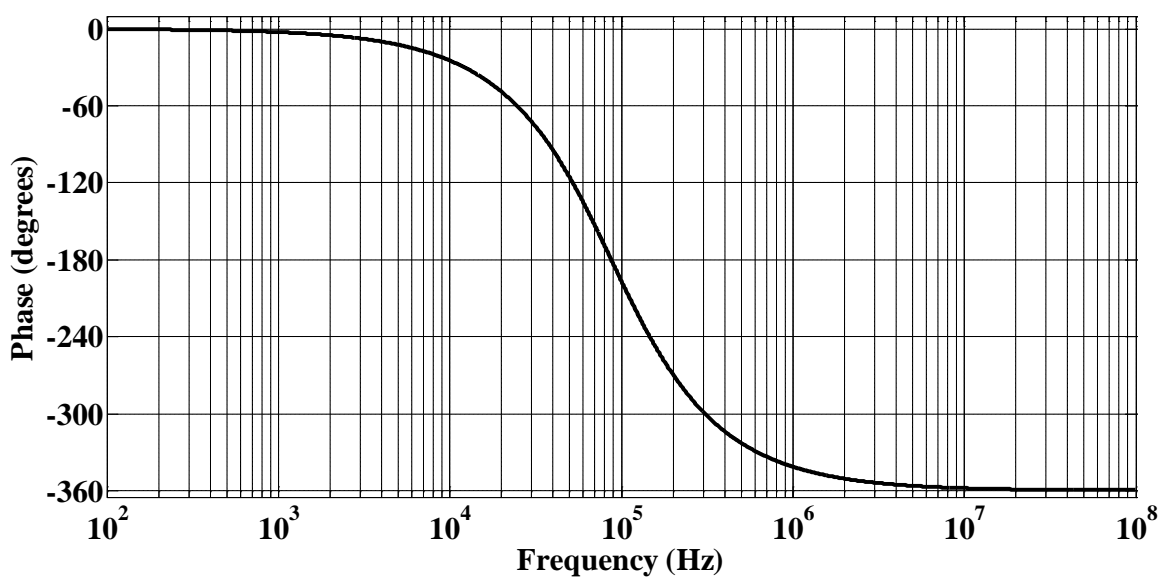

Figure 6. Phase response of all-pass filter.

\section{Conclusions}

A new second order voltage-mode MISO-type universal biquadratic filter using single UVC has been presented. The proposed filter offers following advantages: i) employment of single active component; ii) ability to realize all the basic second order filters without altering the circuit configuration; iii) low active and passive sensitivities; iv) free from component matching conditions; v) independent control of natural frequency and bandwidth. On the basis of above mentioned features of the proposed biquadratic filter, it can be used for various low voltage applications. The workability of the presented circuit configuration has been established by SPICE simulation using $0.18 \mu \mathrm{m}$ TSMC CMOS technology.

\section{References}

[1] Pushkar, K.L., Bhaskar, D.R. and Prasad, D. (2013) Voltage-Mode New Universal Biquad Filter Configuration Using a Single VDIBA. Circuits, Systems, Signal, and Processing, 33, 275-285.

[2] Prasad, D., Bhaskar, D.R. and Singh, A.K. (2009) Multi-Function Biquad Using Single Current Differencing Transconductance Amplifier. Analog Integrated Circuits and Signal Processing, 61, 309-313. https://doi.org/10.1007/s10470-009-9310-1

[3] Keskin, A.U. (2006) Multi-Function Biquad Using Single CDBA. Electrical Engineering, 88, 353-356. https://doi.org/10.1007/s00202-004-0289-4

[4] Bashir, S.A. and Shah, N.A. (2012) Voltage Mode Universal Filter Using Current Differencing Buffered Amplifier as an Active Device. Circuits and Systems, 3, 1-4. https://doi.org/10.4236/cs.2012.33038

[5] Herencsar, N., Koton, J., Vrba, K. and Cicekoglu, O. (2009) Single UCC-N1B 0520 Device as a Modified CFOA and Its Application to Voltage- and Current-Mode Universal Filters. Applied Electronics, Pilsen, 9,127-130.

[6] Shah, N.A., Rather, M.F. and Iqbal, S.Z. (2005) A Novel Voltage-Mode Universal Filter Using a Single CFA. Active and Passive Electronic Devices, 1, 183-188.

[7] Horng, J.W., Chang, C.K. and Chu, J.M. (2002) Voltage-Mode Universal Biquadratic Filter Using Single Current-Feedback Amplifier. IEICE Transactions on Fundamentals, 85, 1970-1973. 
[8] Herencsar, N., Koton, J. and Vrba, K. (2011) KHN-Equivalent Voltage-Mode Filters Using Universal Voltage Conveyors. AEU - International Journal of Electronics and Communications, 65, 154-160. https://doi.org/10.1016/j.aeue.2010.02.005

[9] Minarcik, M. and Vrba, K. (2007) Continuous-Time Multifunctional Filters with Wide Bandwidth Using Universal Voltage Conveyors. Proceedings of the Sixth International Conference on Networking. https://doi.org/10.1109/ICN.2007.32

[10] Pushkar, K.L. and Gupta, K. (2017) MISO-Type Voltage-Mode Universal Biquadratic Filter Using Single Universal Voltage Conveyor. Circuits and Systems, 8, 227-236. https://doi.org/10.4236/cs.2017.89015

[11] Minarcik, M. and Vrba, K. (2006) Low-Output and High-Input Impedance Frequency Filters Using Universal Voltage Conveyor for High-Speed Data Communication Systems. In Proceedings of international conference on networking ICN 2006, Mauritius, 155-158.

[12] Herencsar, N., Koton, J. and Vrba, K. (2009) A New Electronically Tunable Voltage-Mode Active-C Phase Shifter Using UVC and OTA. IEICE Electronics Express, 6, 1212-1218. https://doi.org/10.1587/elex.6.1212

[13] Sponar, R. and Vrba, K. (2006) Measurements and Behavioral Modeling of Modern Conveyors. (IJCSNS) International Journal of Computer Science and Network Security, 6, 57-65.

[14] Herencsar, N., Koton, J., Vrba, K. and Minaei, S. (2011) Electronically Tunable MOSFET-C Voltage-Mode All Pass Filter Based on Universal Voltage Conveyor. (ICCSN) Communication Software and Networks, 442-445. https://doi.org/10.1109/ICCSN.2011.6014931

[15] Minaei, S. and Yuce, E. (2010) Novel Voltage-Mode All-Pass Filter Based on Using DVCCs. Circuits System and Signal Processing, 29, 391-402. https://doi.org/10.1007/s00034-010-9150-3 